\title{
Low frequency of recent parvovirus infection in a population-based cohort of patients with early inflammatory polyarthritis
}

\author{
Beverley Harrison, Alan Silman, Elizabeth Barrett, Deborah Symmons
}

\begin{abstract}
Objective-To determine the contribution of human parvovirus $B 19$ infection in explaining the incidence of early inflammatory polyarthritis (IP) in a population. Setting-The Norfolk Arthritis Register (NOAR) is a community-based programme aiming to ascertain all new cases of IP arising in a population that lead to attendance at primary care.

Subjects-147 newly ascertained subjects with IP with a disease duration of less than 16 weeks.

Methods-Full clinical appraisal of all subjects who were followed up for three years. B19 IgM assayed with a third generation antibody capture enzyme immunoassay.

Results-Only four (2.7\%) patients had evidence of recent $B 19$ infection, only one of whom did not satisfy criteria for rheumatoid arthritis (RA).

Conclusion-B19 infection does not explain more than a small proportion of either RA or undifferentiated IP cases occurring in the population.

(Ann Rheum Dis 1998;57:375-377)
\end{abstract}

Viral infections have a number of important effects on the immune system, and may trigger rheumatoid arthritis (RA) in a susceptible host. Since its discovery in 1975, it has been noted that human parvovirus B19 frequently causes a self limiting polyarthritis in adults. ${ }^{1}$ It has also been debated whether, in some patients, B19 may act as a trigger for RA. Three hospitalbased studies with a combined total of 199 patients with early ( $<1$ year) RA, found that nine $(4.5 \%)$ had evidence of recent B19 infection. ${ }^{2-4}$ By contrast, among 190 patients with unspecified inflammatory arthritis, 23 $(12 \%)$ had recent B19 infection. ${ }^{25}$

The diagnosis of RA is difficult in the early stages, and classification criteria were developed using patients with established disease. ${ }^{6}$ Patients in hospital-based studies are subject to referral bias, and are more likely to have seropositive or erosive disease, or both. We therefore tested the hypothesis that evidence of recent B19 infection would be a frequent finding in patients with inflammatory polyarthritis (IP) newly presenting to primary care. We also hypothesised that the frequency would be higher in those with self limiting disease, and in those who did not develop characteristic features of RA.

\section{Methods}

The study population was recruited from patients with IP referred to the Norfolk Arthritis Register (NOAR). This covers all adults registered with a primary care physician in the Norwich Health Authority (population almost 0.5 million). Patients are referred to NOAR if they have IP (swelling of at least two joints that has persisted for a minimum of four weeks) and a disease onset after January 1990. Patients are excluded from the study if they have an alternative specific rheumatological diagnosis that accounts for their symptoms, apart from RA, psoriatic arthritis or post-viral arthritis. For this analysis, subjects were eligible if they were aged 16-65 years, had a disease duration of less than 16 weeks when first seen, and had been followed up for three years.

Between January 1990 and August 1993, 628 patients were referred to NOAR who were aged between $16-65$ years, of whom 214 (34\%) had a disease duration of under 16 weeks at presentation. Of these, 147 had serum available at baseline and follow up data at three years. These 147 patients form the study population.

A research nurse performed a structured history and examination at baseline. Blood samples were analysed for rheumatoid factor (RF) using a tube latex dilution test. The presence of IgM antibodies to B19 was determined using a third generation antibody capture B19 IgM enzyme immunoassay (Biotrin International). This was similar to the method used by Naides et $a l$ and had no demonstrated cross reactivity with RF. Radiographs of the hands and feet were taken in those patients who satisfied a sufficient number of the 1987 ARA criteria $^{6}$ to be classified as having RA if erosions were present. Disease status of the patients was assigned using two separate approaches. In the first, patients were classified as having RA by applying the 1987 ARA criteria at baseline, in both the traditional "list" format and the classification tree format. Secondly, for patients referred to hospital, the clinical diagnosis made by a consultant rheumatologist was obtained from the hospital case notes.

\section{Results}

The median age of the 147 patients was 47 years (range 19-65) and 104 (71\%) were female. The median disease duration at presentation was 10 weeks (range 4-16). At baseline, 57 patients (39\%) satisfied the 1987 ARA classification criteria for RA in the "list" format, and $86(59 \%)$ in the "tree" format. In total, 36 patients $(25 \%)$ were seropositive for
Accepted for publication 28 April 1998 
Table 1 Clinical characteristics of patients with evidence of recent parvovirus B19 infection

\begin{tabular}{|c|c|c|c|c|c|c|}
\hline \multirow[b]{2}{*}{ Age } & \multirow[b]{2}{*}{$\operatorname{Sex}$} & \multicolumn{2}{|l|}{ Baseline } & \multicolumn{3}{|l|}{ Follow up } \\
\hline & & $\begin{array}{l}\text { Satisfied } 1987 \\
\text { ARA criteria }\end{array}$ & $\begin{array}{l}\text { Rheumatoid } \\
\text { factor }\end{array}$ & Erosions & Final clinical diagnosis & Outcome at three years \\
\hline 34 & $\mathrm{~F}$ & No & Negative & - & IP & Swelling of MCP joints at $1 \mathrm{yr}$ resolved after $2 \mathrm{yr}$ \\
\hline 48 & $\mathrm{~F}$ & Yest & Negative & Yes & RA & Persistent swelling of hands and feet treated with sulphasalazine \\
\hline 52 & $\mathrm{~F}$ & Yes $^{\star}$ & Negative & No & RA & Treated with prednisolone and sulphasalazine \\
\hline 66 & $\mathrm{~F}$ & Yes* & Positive & No & not referred to hospital & Swelling of PIP joints only \\
\hline
\end{tabular}

^Both "list" and "tree" formats; †"tree" format only.

RF. Evidence of recent parvovirus infection was detected in only four $(2.7 \%)$ patients. Furthermore, B19 infection was observed in only one of $61(1.6 \%)$ of those patients who did not satisfy classification criteria for RA. Table 1 shows the clinical characteristics of the patients with recent B19 infection. All were women, and three satisfied classification criteria for RA at baseline, all of whom had persistent symptoms at three years.

\section{Discussion}

The most important finding from this study was that among the 147 patients newly presenting to primary care, and notified to a population register, with IP of less than 16 weeks duration, only four $(2.7 \%)$ had evidence of recent B19 infection. This proportion is lower than that previously reported from early synovitis clinics. $^{235}$ Given this low frequency, we did not attempt to assess the frequency of recent B19 infection among healthy age matched controls. As explained earlier, of 628 patients who met the study entry criteria, only $214(34 \%)$ presented within 16 weeks of disease onset, and were thus eligible for analysis of parvovirus IgM. The time from symptom onset to testing for B19 IgM was relatively short in the four positive cases $(2,3,4$, and 10 weeks) compared with a median time of 10 weeks in those who were B19 negative. It is therefore possible that the frequency of B19 would have been higher if those patients who presented later had the opportunity to be assessed earlier in their disease course.

This study did not attempt to exclude an association between B19 and a community series of patients with IP. Rather it attempted to examine whether B19 explained a substantial proportion, particularly of the mild "undifferentiated" cases arising in the population. It is possible that more cases may have been positive for recent B19 infection if they were recruited during an epidemic of parvovirus infection. Our patients were identified over a four year period, and we were informed by the Norwich Public Health Laboratory that an epidemic had occurred towards the end of recruitment in 1993. Two of the B19 positive cases had a disease onset in 1993, and the others in 1991 and 1992. There was no evidence of clustering of these cases with respect to place of residence.

Three of the four cases had persistent symptoms at three years, two of whom were treated with disease modifying anti-rheumatic drugs (DMARDs) and had a clinical diagnosis of RA. It is impossible to determine whether the association of these cases with recent B19 infection is causal. However, it is important that such patients are not labelled as having "parvovirus arthropathy", which is considered a mild self limiting disease that does not require treatment with DMARDs.

In people with B19 infection, HLADRB $1^{\star} 04$ alleles might increase susceptibility to develop arthritis, ${ }^{8}$ or in those with arthritis, to have persistent disease. ${ }^{2}$ These findings however, are not consistent. ${ }^{19}$ In the NOAR study, one of the patients with recent B19 infection was positive for $\mathrm{DRB} 1^{\star} 04$, but none were positive for $\mathrm{DRB} 1^{\star} 01$ alleles.

Finally, a large number of techniques have been used to diagnose B19 infection, ${ }^{10}$ and it has been debated whether a possible link between B19 infection and RA could be confirmed if more sensitive methods of detection such as polymerase chain reaction were used. For example, B19 DNA has been detected in the serum or synovial fluid cells of infected patients in some ${ }^{11}$ though not all $^{24}$ reports. However, even if B19 DNA is detected at the site of joint inflammation, this is not proof of causation, as it may merely represent a passenger in one of the cell populations attracted to the inflamed synovium. ${ }^{12}$ For example, a recent study from Finland reported B19 DNA in the synovial membranes of 13 of 27 young adults undergoing investigation of joint trauma. ${ }^{13}$ The authors concluded that at present, serology remains the best method for diagnosing B19 arthropathy. However, it has been suggested that improved virological techniques may enable us to determine whether patients with arthritis have persistent B19 infection, or whether B19 has acted as a trigger for the development of RA. ${ }^{14}$ We are grateful to the Arthritis Research Campaign for funding
this work, and thank the NOAR research nurses and staff (Joan Barnard, Diane Bunn, Jackie Chipping, Linda Galpin, Sue Barnard, Diane Bunn, Jackie Chipping, Linda Galpin, Sue
Ivins, and Sue Whiting) for all their hard work. We also acknowledge the support of the general practitioners and hospital staff of the Norwich Health Authority. We are grateful to Dr Ali Hajeer (ARC Epidemiology Unit) for helpful discussions during this study, and to Mr Les Martin (Department of Virology, Withington Hospital, Manchester) for performing the B19 assays.

This work was funded by the Arthritis Research Campaign

1 Woolf AD, Campion GV, Chishick A, Wise S, Cohen BJ, Klouda PT, et al. Clinical manifestations of human parvovirus B19 in adults. Arch Intern Med 1989;149:1153-6.

2 Cohen BJ, Buckley MM, Clewley JP, Jones VE, Pittick AH, Jacoby RK. Human parvovirus infection in early rheumatoid and inflammatory arthritis. Ann Rheum Dis 1986;45: $832-8$.

3 Taylor HG, Borg AA, Dawes PT. Human parvovirus B19 and rheumatoid arthritis. Clin Rheumatol 1992;11:54850 .

4 Nikkari S, Luukkainen R, Möttönen T, Meurman O, Hannonen P, Skurnik M, et al. Does parvovirus B19 have a role in rheumatoid arthritis? Ann Rheum Dis 1994;53:106-11. 5 White DG, Mortimer PP, Blake DR, Woolf AD, Cohen BJ, White DG, Mortimer PP, Blake DR, Woolf AD, Cohen BJ,
Bacon PA. Human parvovirus arthropathy. Lancet 1985:i: Bacon PA. 
6 Arnett FC, Edworthy SM, Bloch DA, McShane DJ, Fries $\mathrm{JF}$, Cooper NS, et al. The American Rheumatism Association 1987 revised criteria for the classification of rheumatoid arthritis. Arthritis Rheum 1988;31:315-24.

7 Naides SJ, Scharosch LI, Foto F, Howard EJ. Rheumatologic manifestations of human parvovirus B19 infection in adults. 1990;33:1297-309.

8 Klouda PT, Corbin SA, Bradley BA, Cohen BJ, Woolf AD. HLA and acute arthritis following human parvovirus infection. Tissue Antigens 1986;28:318-19.

9 Nikkari S, Hannonen P, Möttönen T, Luukkainen R, Yi-Jama T, Toivanen P. Persistence of parvovirus B19 in synovial fluid and bone marrow. Ann Rheum Dis 1995;54: $597-600$
10 Naides SJ. Parvovirus B19 infection. Rheum Dis Clin North Am 1993;19:457-75.

11 Wolf AD, Campion GV, Klouda P, Chiswick A, Cohen B, Dieppe PA. HLA and the manifestations of human parvovirus B19 infection. Arthritis Rheum 1987:30 (suppl):S52

12 Clewley JP. Polymerase chain reaction assay of parvovirus B19 DNA in clinical specimens. J Clin Microbiol 1989;27: 2647-51.

3 Söderlund $M$, von Essen R, Haapasaari J, Kiistala U, Kiviluoto O, Hedman K. Persistence of parvovirus B19 DNA in synovial membranes of young patients with and without chronic arthropathy. Lancet 1997;349:1063-5.

14 Woolf AD, Cohen BJ. Parvovirus B19 and chronic arthritis causal or casual association? Ann Rheum Dis 1995;54: $535-6$.

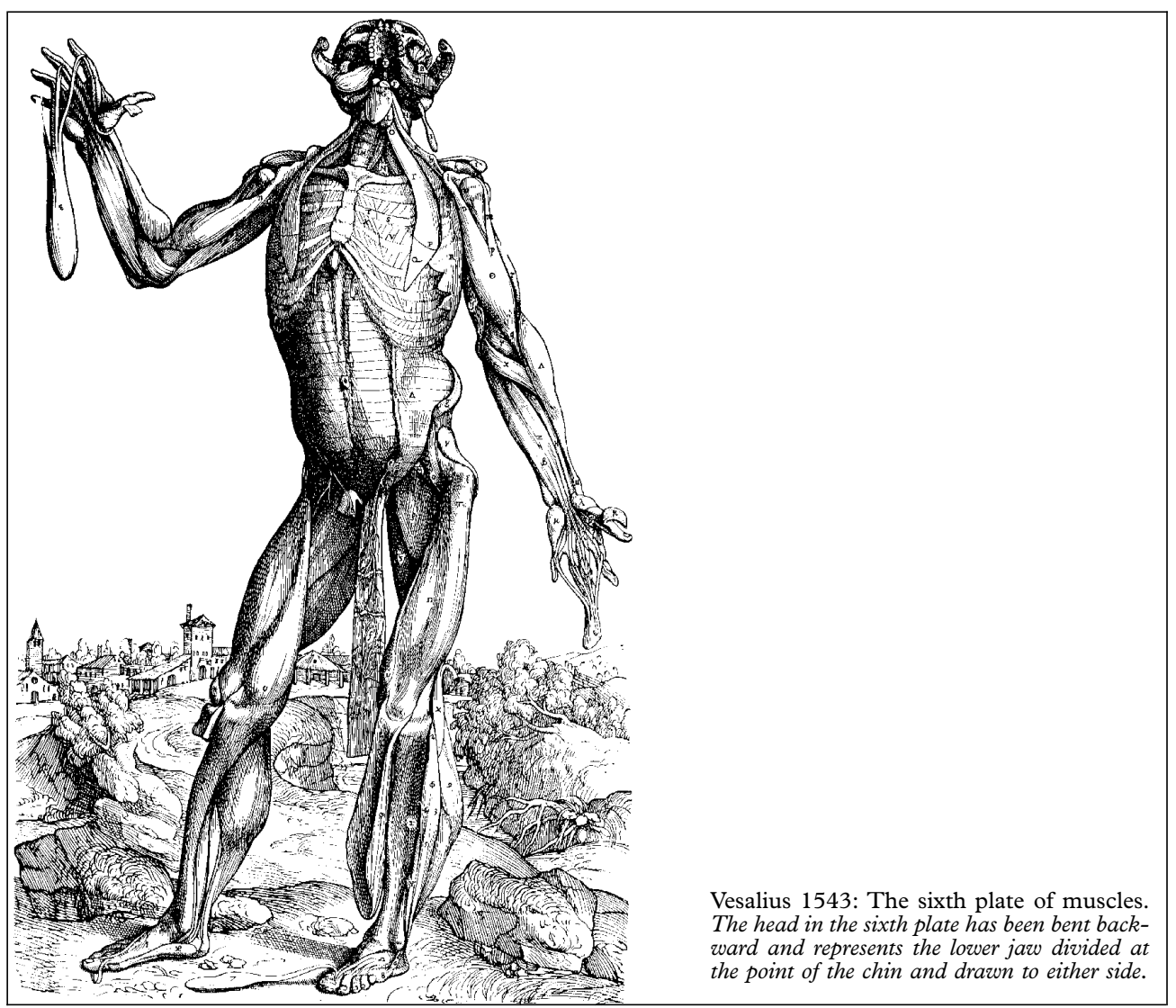

